\title{
ALIGNING CAPABILITIES AND SOCIAL MEDIA AFFORDANCES FOR OPEN INNOVATION IN GOVERNMENTS
}

\author{
Andrea Malsbender \\ University of Muenster - ERCIS \\ Muenster, Germany \\ andrea.malsbender@ercis.uni-muenster.de \\ Sara Hofmann \\ University of Muenster - ERCIS \\ Muenster, Germany \\ sara.hofmann@ercis.uni-muenster.de \\ Jörg Becker \\ University of Muenster - ERCIS \\ Muenster, Germany \\ joerg.becker@ercis.uni-muenster.de
}

\begin{abstract}
In recent years the proliferation of a new technological evolution has aroused great interest from science and practice: social media. Subsuming different types of online applications where users can create, edit and share content, social media enables new forms of interaction with others. Organisations already recognise its relevance and start leveraging on it. Furthermore, organisations identify the role of service innovation as one major driver for economic growth and competitive advantage. Nevertheless, although social media affords organisations to interact with their customers, the potential for utilising it for improving their service innovation activities is almost unexploited yet. Therefore, this paper aims at providing a framework for supporting the use of social media affordances for service innovation. Its applicability is tested in the domain "government". Based on theoretical constructs a conceptual analysis is presented, tested in a specific domain and supplemented by potential future research and implications for theory and practice.
\end{abstract}

Keywords: Innovation, open innovation, innovation capabilities, government, egovernment, social media affordances.

\section{INTRODUCTION}

The rise of social media technologies has provided organisations with new ways of engaging with their customers. Besides publishing information, advertising products or recruiting employees (Gregurec et al. 2011), companies increasingly use social media for open innovation activities, i.e. they integrate their customers' suggestions into the innovation process. As companies need to stay competitive, they constantly have to search for innovations and implement them based on the needs, wishes and demands of their customers to prevail against competitors (Menor and Roth 2007). Although public administrations differ from private sector companies as they do not have to compete with each other, governments, too, start to utilise social media for new ways of interacting with citizens, associations as well as organisations in open innovation activities (Hofmann et al. 2013). Their main drivers are the needs for saving costs, offering improved services and considering citizens' needs in a digitalised environment (Bekkers et al. 2006). Swedish municipalities, for instance, have formed a network for collaborating both with each other as well as with citizens and organisations in order to increase their innovation potentials (Feller et al. 2010). Studies also suggest that taking part in open innovation 
initiatives leads to an increased knowledge management for governments (Chaston 2012). However, all in all, open innovation in government is still in its infancy (Lee et al. 2012). Although open innovation initiatives in the private sector are further advanced, a clearly structured process on how to leverage social media technologies for open innovation is missing there, too. Motivated by this gap in the literature, our research objectives are the following: Based on the existent literature, we (1) identify the general capabilities that are required for service innovations as well as the affordances of social media for engaging with customers. Afterwards, we (2) develop a framework that matches the service innovation capabilities with the social media affordances in a structured way in order to identify how social media can support service innovation capabilities. Finally, we (3) apply this framework to the government domain and analyse how governments can use social media to foster open innovation in social media.

The remainder of our article is structured as follows. In the next section, we illuminate service innovations from a general viewpoint. Based on the dynamic capability theory, we identify six service innovation capabilities. Furthermore, we review the related work on social media before depicting the use of social media and especially its adoption for open innovation in governmental agencies. Based on this fundament, we develop a domain-neutral framework that matches service innovation capabilities and social media affordances in the following section. In doing so, we first identify social media affordances for engagements with customers and subsequently attribute them to the service innovation capabilities they can support. In order to test our attribution as well as to identify the potentials of social media for open innovation in public agencies, we apply the framework to the government domain in the following section. We also outline challenges that governments might face as well as further positive effects in using social media besides developing service innovations. Afterwards, we discuss our results before finally summarising our findings and giving an outlook to future research questions.

\section{RELATED WORK}

\section{Service innovation}

During the last decade, research on innovation, originally introduced by Schumpeter (1934), experienced a shift from solely focussing on innovations related to technological artefacts, respectively products, to research concerning both, products and services (Johnson et al. 2000; Spohrer and Maglio 2008). As a result service innovation has become a focal point of attention. According to Den Hertog et al. (2010, p. 494), a "service innovation is a new service experience or service solution that consists of one or several of the following dimensions: new service concepts, new customer interaction, new value system/business partners, new revenue model, [or] new organizational or technological service delivery system." The role of service innovation for economic growth and sustainable competitive advantage is increasingly recognised and acknowledged by managers of service organisations (Menor and Roth 2007). Especially, issues regarding design and development aspects are highlighted (Menor et al. 2002) and an extensive literature stream on service management, service marketing, service innovation, service-dominant logic perspective, open service innovation and, generally, service science already exists (Den Hertog et al. 2010). Nevertheless, as Menor and Roth (2007, p. 825) state, "current theory and understanding of the strategies and tactics for developing new services is inadequate". This is reflected by the fact, that, despite the significant rise of research on service innovation, many service firms still have to cope with their innovative efforts (Jong and Vermeulen 2003). Due to the individual character of services, specific capabilities for managing new service development are needed. Generally, an organisation's capabilities can be differentiated into two types: operational capabilities and dynamic capabilities. Operational capabilities are needed to perform "a coordinated set of tasks utilizing organizational resources, for the purpose of achieving a particular result" (Helfat and Peteraf 2003, p. 999). Such capabilities are, e.g., marketing campaigns or distribution logistics (Collis 1994). Dynamic capabilities, introduced by Teece et al. (1997), are the organisation's ability to "integrate, 
build and reconfigure internal and external competencies to address rapidly changing market environments" (Teece et al. (1997), p. 516). For the development and management of new service experiences or solutions, six main dynamic service innovation capabilities are needed (Den Hertog et al. 2010). First, the organisation must be able to both, understand their customer by sensing their needs and promising technological options. Second, the organisation needs the ability to detail and visualise services gradually and to conceptualise each component of the new service solution (e.g. target audience). Third, as service innovations are often new configurations of existing elements, the organisation needs to be able to configure or (un-)bundle existing service activities to generate value. Fourth, due to dependencies on other 'co-designers' of the new service, the organisation needs the capability to manage the service innovation across existing boundaries. Fifth, for the introduction of the new service, the organisation has to be able to scale and stretch the service innovation from an experimental (i.e. R\&D) to an organisation wide setting. Sixth, based on already implemented innovation activities, organisations need to be able to learn from experiences and to adapt the overall service innovation process with respect to past failures and successes.

\section{Social media}

Social media has experienced a tremendous growth over the last decades and is increasingly recognised by organisations. Motivated by the success of first movers, in 2003 the development of many social media technologies (e.g. MySpace, LinkedIn) (Boyd and Ellison 2007) led to new ways for individuals to interact with others and for organisations to engage with customers (Rishika et al. 2013). According to Bolton et al. (2013) and Kaplan and Haenlein (2010), we define social media as a group of online applications through which users are allowed to create, edit, evaluate, share and/or link to a variety of user-generated content or to other users. This broad view of social media allows for the classification into different categories (e.g. photo services (Flickr), music services (YouTube), weblogs etc.). Most of existing research focusses on two main social media technologies: social network sites (or online social networks or social networking sites), like Facebook, and microblogging services, like Twitter. This is caused by the fact, that conversations, reactions and personal information of users can be gathered and analysed easily. Social network sites are web-based platforms, users can "(1) construct a public or semi-public profile within a bounded system, (2) articulate a list of other users with whom they share a connection, and (3) view and traverse their list of connections and those made by others within the system" (Boyd and Ellison 2007, p. 211). Furthermore, they can be differentiated into interorganisational (so called enterprise social networks (ESN)) and public available social network sites (SNS). Our research is not limited to a specific technology since different technologies enable different types of engagement with customers/citizens and can be leveraged diversely.

\section{Open innovation in government}

In contrast to organisations, governments took their time before using social media on a large scale. An analysis of Facebook pages in Germany revealed that as of March 2012 only 12 of the 25 largest cities had actually launched a government page on Facebook (Hofmann et al. 2013). However, since then, public administrations have increased their social media activities and meanwhile use this new way of communication for various purposes. These new technologies are not only suitable for providing information to citizens but also for actively engaging and incorporating their ideas into government decisions (Lee and Kwak 2012). A popular branch of governments' social media activities that summarises this trend is subsumed by the term open government, which was coined by US president Barack Obama. He defined open government as "creating an unprecedented level of openness in Government" (Obama 2008). This can be achieved by the three steps transparency, participation and collaboration. In order to reach the postulated goals, adequate technologies are needed to enable these steps. Whereas transparency refers to providing information about government activities, participation 
and collaboration involve the active contribution and integration of citizens into the processes of government.

A promising way of integrating citizens into these processes is via open innovation (Feller et al. 2010). Open public innovations in this context are understood as "processes of coproduction between public agencies, nongovernmental organizations and community-based organizations" (Edwards 2006, p. 175). On the one hand, taking part in open innovation activities increases the sense of community among the citizens because they feel that they have created value for their community. On the other hand, open innovation projects can improve government services, which is a crucial requirement for public agencies. The concept of open innovation has spilled over from the private sector where companies have long been relying on external resources for designing innovations (Feller et al. 2010). Open innovation has mainly been considered for businesses since innovations are often the outcome of a competition race between several companies. Furthermore, innovations go along with revenue models, which governments do not develop. However, open innovation is not limited to the firm level (Koldzin 2011). The need for integration and interoperability of (e-)government services forces governments to re-invent themselves (Kinder 2010). In the UK, e-government projects have been found to reduce process costs within the administration. Nevertheless, service delivery towards the citizens could not be improved. Furthermore, e-government projects have so far only focused on technical perspectives but neglected the users' side thus achieving only little improvements (Feller et al. 2010). In order to foster innovations, which are essential for modernising governments, co-design between public authorities and citizen communities is a valuable instrument in achieving innovation. Codesigning services by governments and other stakeholders is regarded as a central element in the capability to innovate. Besides the benefits of improved services and an increased sense of community, open innovation is also a reaction to financial deficiencies in the public sector (Chaston 2012). In case expert knowledge is not accessible or simply too expensive, open innovation solutions offer a valuable alternative. Especially online open innovation is much cheaper and more time-saving compared to traditional calls for proposals (Mergel 2011). However, open innovation does not simply mean setting up a social media site but it goes along with several success factors. A prerequisite for successful open innovation activities is the provision of data, i.e. open data that citizens can use for developing their ideas (Thoreson and Miller 2013). Furthermore, governments need to be aware that open innovations will cause changing business models. Therefore, innovation activities need to be aligned with the governments' strategy (Lee et al. 2012). Since governments need to be aware both of their capabilities required for successful service innovation as well as the advantages that social media as platforms for open innovation offer, we develop a framework that matches service innovations capabilities with social media affordances and apply it to the governmental context.

\section{DEVELOPING A FRAMEWORK FOR SOCIAL MEDIA AFFORDED INNOVATION}

Taking the theoretical stance of affordances and dynamic capability theory, we introduce a framework for service innovation enabled by social media. Therefore, we present affordances of social media for engaging with external users. Subsequently, we allocate the resulting affordances to each service innovation capability. The resulting framework can be used to analyse the usability of social media for service innovation in different domains.

\section{Social media affordances for engagement with customers}

Social media technologies afford users in various ways depending on specific domains and set of actions. Taking an affordances lens allows for determining which action potential can be taken by using a specific technology (Leonardi 2011). Previous work on social media affordances focuses on their use within organisations. On the one hand, Treem and Leonardi (2012), focus on the affordances of social media for organisational communication in general. In particular, they identify four types of affordances, each divided into sub-affordances. First, they highlight the visibility of employees' 
behaviours, knowledge, preferences, and network connections provided by social media. Second, social media enables persistent access to information as it remains accessible as originally provided by the author. Third, social media affords users to edit information individually before it is viewed by others (e.g. profile information or content). Fourth, the affordance association is the option of connections between users as well as users and content. On the other hand, Majchrzak et al. (2013) also present four affordances from a knowledge sharing/management perspective and based on the identified types by Treem and Leonardi (2012). First, social media enables metavoicing, which is the ability to engage in ongoing online conversations. Second, users (resp. employees of an organisation) can attend knowledge conversations triggered by timely automated alerts caused by changes to a specific content of interest. Third, network-informed association affords users to engage in conversations based on relational ties to other users or content ties to specific information. Fourth, users are afforded to conduct a generative role-taking, i.e. they can engage in conversations with individually defined roles in order to maintain a productive dialogue.

Contrary to existing research on social media affordances for an organisation's internal use of social media, we focus on the affordances of social media for external interaction with unknown users (customers or citizens). In doing so, we change the context from internal to external and the task from general conversations or knowledge sharing to innovation design. Based on the literature, our definitions of these affordances are the following:

Visibility. Social media affords visibility of content, previously invisible in real life, to other users (individuals or organisations) (Treem and Leonardi 2012). On the one hand, in most social media technologies users provide information about their personal profile and their personal situation and habits by describing their age, location, interests and preferences. Such information becomes visible to other users and can easily be analysed (Boyd and Ellison 2007). On the other hand, users are able to contribute (post) or consume (lurking or observing) content, opinions or general information. Thereby, each contribution leads to visibility (in some cases circumscribed by privacy settings). Once, content is visible, the consumption of information is possible (Bolton et al. 2013).

Visibility is the ability of social media to make content generated by users (e.g. ideas, information, personal preferences) visible to other users (people or organisations).

Persistence. Information in social media is persistent over time. Constituted by the fact, that even when a user 'logs out' of a social media technology, the information or content s/he provided is still accessible for other users (Treem and Leonardi 2012). Thereby, information is presented in the same form as it was displayed by the content generator and cannot be changed by other users.

Persistence is the ability of social media that content (e.g. posted ideas) remains accessible over time in the same form as the original display after the actor has finished his or her presentation.

Editability. The affordance editability refers to two main features provided by social media technologies (Treem and Leonardi 2012). First, users are able to form their contribution in isolation and in an asynchronous setting before presenting it to others. Second, users can change (modify or revise) content communicated in the past. The latter is particularly relevant in wikis where editing helps improving the quality of existing content.

Editability is the ability of social media that content (e.g. ideas) can both, be generated in isolation and updated and refined by users (also influenced by other users' reaction).

Association. Social media technologies provide access to social networks of users, their knowledge, opinions and experiences (Rishika et al. 2013). In most of these technologies connections are displayed (dependent on privacy settings), which enables tracking other users through the network graph (Boyd and Ellison 2007). Furthermore, based on profile information users can be associated with content. This content can vary from preferences (e.g. "liking" of music styles) over following (e.g. specific actors or 
athletes) to associations resulting from the "about me" section (e.g. preferences regarding political or religious orientation).

Association is the ability of social media to allow for associating ideas, people and other content. Associations exist in two forms: first, an individual can be associated with another individual (social ties). Second, an individual can be associated with a piece of information (content).

Metavoicing. With respect to the original interpretation of this affordance by Majchrzak et al. (2013), metavoicing in social media generally affords users to react on content presented by other users. This feedback is generally sought by users posting an idea, content, or critical comment. As social media allows for feedback independent of specific skills or knowledge (e.g. "tweets" can be placed without any connection to a person or organisation in real life), it enables users to articulate their opinion to others' postings.

Metavoicing is the ability of social media to enable users to react to others' content (e.g. ideas, content, discussions, surveys, or polls).

Generativity. Social media enables users to articulate their ideas or opinions. Based on postings contributing content, creating or combining multiple sources, their personal preferences and thinking can be presented to others (Bolton et al. 2013). This user-generated content is visible (visibility) to other users, can be commented (metavoicing) or connected (association).

Generativity is the ability of social media to enable users and communities to engage, learn, and innovate by expressing service ideas and service experiences.

\section{Social media affordances for service innovation framework}

With respect to the affordances and the requirements specified by the dynamic service innovation capabilities, we present the underlying framework matching these theoretical constructs (see Figure 1). Therefore, we define for each capability the affordances having supportive features. Generally, as each affordance supports all of the capabilities in varying degrees, we focus on highly relevant aspects. Furthermore, although both perspectives (customer and organisation) can be afforded by social media, our focus is the benefit for the focal organisation.

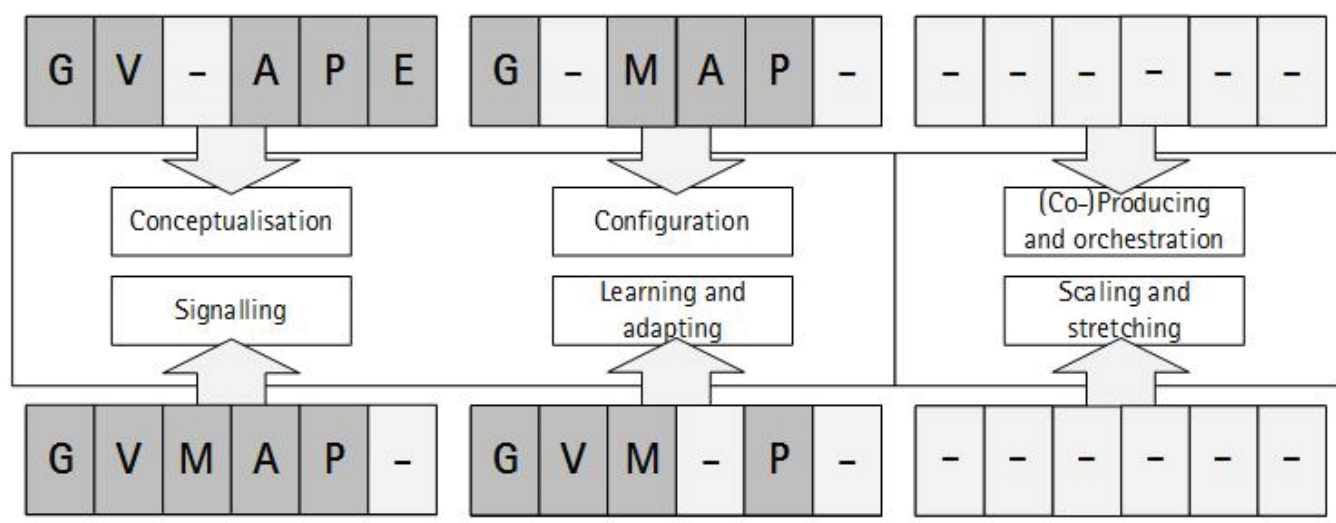

Figure 1. Social media affordances for dynamic service innovation capabilities

(cf. Den Hertog et al. 2010)

Signalling of customer needs and technological developments. Organisations constantly have to sense for customer needs and technological options (Den Hertog et al. 2010). For this purposes, they 
can leverage social media based on the affordances generativity $(G)$, visibility $(V)$, metavoicing $(M)$, association $(A)$ and persistence $(P)$. First, organisations can benefit from generativity initialising competitions motivating customers to present new innovations addressing a specific topic. Second, organisations can present new ideas open for discussions. Third, they can articulate a need for a new technology and for suggestions by experts (without paying salaries) to an unknown audience. Fourth, organisations can present activities (i.e. competitions) related to innovations conducted by the organisation. Overall, generativity supports both, engagement with and learning from customers and their experience. Visibility of social media supports signalling by enabling access to formerly inaccessible information. Organisations can extract customer opinions, experiences, or innovative ideas that become visible through social media and thereby identify potential needs. Therefore, they can screen all existing (posted by users) ideas, technologies, innovations etc. Second, based on profile information, the organisation can deduce implicit needs (Kotler 1988). Metavoicing supports signalling by reacting to comments/posts regarding an organisation's own innovative activities or by reacting or commenting on innovations presented by customers. Having an interactive relationship with customers improves customer perception of the overall organisation. Based on content-related associations, potential innovations similar to already existing services can be identified by use of the affordance association. First, the organisation can identify who is interested in being part of 'the organisational activities' (follower, group associations etc.). These connections can be used to classify target customers based on their behaviours. Second, the organisation can identify potential experts within 'their network'. As information in conversations (comments, criticism etc.) is persistent over time, organisations can benefit from this affordance by analysing changes in the market environment, needs and thinking of the customers. Furthermore, the service innovation development processes are documented over time.

Conceptualisation. Within a conceptualisation of a new service innovation, organisations need to consider all relevant information (Den Hertog et al. 2010). For this purpose, different affordances can be helpful for an organisation: generativity $(G)$, visibility $(V)$, association $(A)$, persistence $(P)$ and editability $(E)$. Organisations can benefit from generativity by motivating customers to present relevant components that need to be considered within a conceptualisation of a new service innovation to improve quality. First, to allow for this engagement of the customer, this affordance enables organisations to present a concept to a wide audience. Second, by presenting a concept, the organisation can test whether it is understandable and even feasible from a customer's point of view. Visibility can be utilised during conceptualisation by screening information about ideas, technological changes or opinions as input for new service concepts. Furthermore, organisational activities (e.g. the new service development) become visible and can improve awareness of customers for co-creation. By use of association, the organisation can access relevant information. Especially, information about the target audience (including detailed descriptions of their profiles) can be extracted based on a classification of relationships (people or content). Furthermore, the organisation can benefit by searching for relevant aspects for the new service concept through associated content (e.g. competitors in this field or feasibility of the new concept based on experiences). Organisations can benefit from persistence by incrementally developing new service concepts over time (Treem and Leonardi 2012). Customer activities, ideas, and comments endure over time and can be used as potential input that needs to be considered within the conceptualisation of new services. Editability enables the organisation to work on existing components of a service concept. In doing so, every follower is informed about the changes and can react directly. Based on customer's comments to a presented concept, the conceptualisation can progress incrementally to improve the quality of the resulting solution.

Configuration. Aiming at (un-)bundling existing service activities to generate value for customers (Den Hertog et al. 2010), organisations can notably benefit from the affordances generativity $(G)$, metavoicing $(M)$, association $(A)$ and persistence $(P)$. Generativity affords organisations to include customers' opinions and experiences regarding feasibility of a new service bundle. Thereby, motivated 
for contribution, the external view of targeted customers can be included in analysing the fit of the requirement (customer) and capability (organisation). Based on a request for innovative suggestions by customers, organisations are afforded by metavoicing to react to and discuss potential new service combinations. Furthermore, they can discuss potential benefits of new combinations. By association, organisations can identify potential service bundles based on preferences of customers. For instance, a customer who has connections to two different existing services (preferences) has a tendency to prefer a combination of those. Furthermore, affiliated in a group, additional service preferences can be derived based on others' preferences. Persistence supports storing past experiences for configuring existing service components in a new way (e.g. feedback to bygone service innovation activities to identify potential combinations of existing services). Furthermore, customer needs can show whether new combinations should be bundled or existing bundles of service activities should be provided individually.

Learning. Organisations are constantly forced to learn from past activities. Especially, learning from failures or success of past service innovation endeavours can be supported by the affordances generativity $(G)$, visibility $(V)$, metavoicing $(M)$ and persistence $(P)$ of social media. Generativity enables organisations to learn from experiences by actively asking for environmental reactions on implemented service innovations in the past. Thereby, the organisation can use technologies like polls or motivate customers to comment on these activities. Particularly, the opportunity to receive direct feedback by the 'real' customer and the opportunity to reach many customers is a benefit which is only afforded by social media. Organisations can use visibility by analysing environmental reactions to implemented service innovations in the past. Therefore, analyses of marketing campaigns or brand perception (especially for product development) have become focal points of attention for organisations. Sentiments regarding new products or services can be analysed (Bollen et al. 2011) and views of different customers (profile information) can be clustered regarding their relevance. Organisations can benefit from metavoicing by being able to react to comments or posts on their past activities. In doing so, they are able to learn from customers' perceptions of their service innovations. Furthermore, they can divert an existing conversation to focus on specific topics of interest. Being able to directly communicate with formerly unknown customers enables receiving concrete feedback. Organisations can benefit from the affordance persistence by analysing reactions on past service innovations. Furthermore a long-term analysis of failures and successes can be conducted. This analysis can then be used to identify (learn) potential for improvement for future activities.

Co-producing and orchestration, and scaling and stretching. For these capabilities none of the present affordances can be leveraged reasonably. As these capabilities primarily require internal or inter-organisational (with partners etc.) interaction, which is out of scope in our framework, none of the affordances for interaction with customers support auxiliary value.

\section{APPLYING THE FRAMEWORK TO OPEN INNOVATION IN THE PUBLIC SECTOR}

Like private sector companies, governments require dynamic service innovation capabilities to provide new services to citizens. They need to be able to "adapt to developments in different political, socioeconomic, technological and cultural environments" (Bekkers et al. 2006, p. 10). Furthermore, governments need to "anticipate the needs of different stakeholders in these environments, such as citizens, companies, societal organizations and other government organizations". As shown above, these capabilities can be supported by the affordances of social media. In order to identify the advantages which arise for governments by using social media in open innovation processes, we apply the previously developed framework to a government context.

Signalling. In contrast to businesses, governments do not compete with other organisations due to their monopoly in offering public services. However, they, too, are facing financial shortcomings and need to cut costs (Chaston 2012). This goal can be achieved by electronic services which can be processed 
with fewer resources. Nevertheless, the adoption of e-government services suffers from citizens refraining to use these services, which can partly be attributed to citizens' distrust towards the government (Bélanger and Carter 2008). Oftentimes, citizens feel that their interests are ignored by the government. In order to counteract this negative image, especially governments need to have the capability to sense citizens' needs. Generativity in social media allows to actively ask citizens to make suggestions to a challenge that the administration is facing. Similar to this co-design approach is for instance participatory budgeting (http://www.participatorybudgeting.org.uk/). Furthermore, the site challenge.gov offers US public bodies the possibility to post calls for participations asking citizens and organisations to contribute to solving a challenge. In order to identify citizens' needs and wishes, governments can furthermore screen citizens' posts on governments' social media sites (visibility). Citizens can also create petitions via social media (e.g. GoPetition 2013) and thus display their wishes to public administrations. Metavoicing allows governments to lead conversations into a certain direction or raise specific questions of interest. Furthermore, it helps identifying citizens' preferred ideas, e.g. based on the number of likes or the polarity of the answers. From a crowdsourcing perspective, citizens can jointly develop service ideas by building on and reacting to others' posts. In doing so, innovations will contain several perspectives and thereby improve their quality. Due to associations between citizens as well as between citizens and topics, governments can identify and address groups in social media that are concerned with a certain topic. In doing so, they can later on extract relevant content from these groups (cf. visibility). It is especially useful for governments since politically or locally active groups connect via social media. Persistence, which is an enabler for the other affordances in service innovation, supports governments' innovation capabilities in several ways. On the one hand, governments can analyse changes in the environment by extracting the stored information on the social media sites of other actors (cf. visibility) and thus identify requirements for their own services. They could, for instance, identify the potential to offer further mobile government services by identifying discussions that point at an increasing interest in mobile apps. On the other hand, permanently stored information enables them to evaluate how successful service innovations have evolved through past discussions on their social media site. Therefore, governments can deduce how to behave in future service innovation activities.

Conceptualisation. As government services address the whole population, i.e. from youths to elderly people, it is crucial to develop target group-specific services or to group the services according to life events. Elderly people, for example, are more likely to come to the governments' sites in person whereas younger citizens prefer using electronic services (Plattfaut et al. 2013). The affordances of social media can help governments to thoroughly conceptualise their services and business models. In addition to the advantages for signalling, social media can support the conceptualisation of new government services in various ways. Governments can present new concepts for services via social media to which citizens can respond (generativity). The Government Digital Service of UK government (https://twitter.com/gdsteam), for instance, publishes information on newly released services on Twitter and asks their followers to comment on it. Citizens can use the social media sites of governments for expressing their opinions of government services (visibility). As an example, citizens complained about too slow reactions of their government on the Twitter account of @gov (https://twitter.com/gov). Metavoicing is especially interesting for services that address a younger target group since this part of the population belongs to the heaviest users of social media (Statista 2012). Governments can evaluate a service concept by aggregating 'likes' as well as the streams of discussion. Furthermore, social media affords governments to identify the needs of special target groups by following specific associations. For instance, university social media groups might reveal important information about how to tailor government services to the target group students. Since social media posts are stored (persistence), governments can learn from past social media discussions and thus extract information relevant for the service conceptualisation. Especially in wikis, governments can react to citizens' critique and suggestions by editing the proposed service (editability). The San Francisco Homeless Resource Wiki, which is jointly operated by different interest groups and the city council, contains services for homeless 
people that can be edited by everyone (http://sfhomeless.wikia.com/wiki/San_Francisco_Homeless_Resource).

Configuration. In the governmental context, completely new services are seldom created from scratch as this would in most cases go along with major changes in the law. A typical way of structuring government services is to bundle them according to phases of life (http://www.qld.gov.au/queenslanders/). Furthermore, governments might leave the core of the service unchanged but add another communication channel (e.g. the mobile channel). Although, social media offer some benefits for configuration, compared to the capabilities signalling and conceptualisation, these advantages are rather minor ones. Governments can post their configured service bundles and ask for citizens' comments (generativity). Furthermore, they can scan the citizens' contribution (visibility) or they can follow discussion streams (metavoicing) in order to identify hints for service configurations. By analysing groups of interests (association) or past discussions (persistence), governmental agencies might get ideas for new configurations. However, currently we do not see any real world scenario in which configuration would be supported by the affordances of social media.

Learning. Up to now, some governments struggle with implementing an efficient knowledge management (Martin 2003). As open innovation is a rather new field for governments (Lee et al. 2012), they have to identify best practices and learn from their experiences. Furthermore, since government communication has mainly been mediated via mass media in the past and since Public Relations departments in public administrations are often understaffed (Fisher Liu and Horsley 2007), governments have to figure out how to address citizens directly via social media - be it for open innovation activities or in general. Governments can ask their citizens for direct feedback on previous service innovations as well as on the service innovation process on social media (generativity). This will help them to understand the citizens' perspective of how their services both are created and perceived. Examples from Turkey and Germany, for instance Barnett (2013) and Thaa (2013), suggest that people felt overlooked in public decisions. Such misunderstandings could be accounted for through a productive dialogue on social media. Analysing citizens' posts (visibility) on the governments' own social media site as well as in dedicated groups will help governments understand how the public perceives both the process as well as a service innovation itself. This is important since government services often go along with submitting private information and governments need to learn about citizens' privacy concerns (Bélanger and Carter 2008). Social media allow governments to directly address citizens by reacting to their posts (metavoicing). In doing so, they can interfere in the conversations such that they can learn how citizens have perceived previous service innovations. Furthermore, they can analyse and evaluate citizens' reactions (in terms of 'likes', comments, retweets etc.) on specific topics and identify best practices as well as improvements for future open innovation activities. As past content is stored in social media, governments can access all relevant information and use them for analysis purposes (persistence, cf. generativity, visibility, and metavoicing).

\section{DISCUSSION, CONCLUSION, AND LIMITATIONS}

The developed framework provides a structure that shows how service innovation capabilities can be supported by social media. Although, matching the social media affordances and capabilities worked quite well, the classification has not been completely unambiguous. In general, every social media affordance can somehow support most of the service innovation capabilities. However, we matched them only if an affordance provided a real value to a capability. The framework shows that especially generativity, visibility and metavoicing are affordances supporting the open innovation process to a high degree. It becomes clear that mainly the first steps in an innovation process represented by the capability signalling can benefit from open innovation approaches.

From a governmental point of view, the framework has revealed several advantages and potential steps for governments to foster open innovation activities in social media. All proposed capabilities except 
for configuration can be supported by social media activities. However, despite their advantages for governments, open innovation campaigns in social media provide several challenges. Benefiting from generativity, for instance, requires resources to identify relevant contributions by citizens. This is regarded as one of the grand challenges for governments' (and organisations' in general) social media activities (Chun and Warner 2010). For visibility, too, resources and technological limitations play an important role in extracting relevant information. In addition, governments need to reassure their citizens that searching their profiles and their posts will not be used for purposes other than generating innovations. When extracting information from metavoicing, governments need to make sure to invest sufficient time and personnel resources. Furthermore, they should abstain from influencing the conversations amongst citizens in such a way that citizens do not feel that their ideas will not be appreciated. Certainly, public bodies need to ensure that their activities are not regarded as propaganda (Fisher Liu and Horsley 2007) and that browsing through their citizens' associations is not considered to be espionage. Persistence raises the issue of a comprehensive strategy to archive previous discussions. Finally, for editability, governments need to keep track of their previous posts. What is more, editing old statements needs to be done in a transparent way in order to prevent the suspicion that governments try to conceal previous actions.

In addition to the described advantages, the six affordances come along with further positive side effects for governments. Generativity, for instance, can also contribute to creating a sense of community among the citizens since they feel that their ideas are appreciated by government. This may strengthen the ties between government and citizens. Similarly, visibility can connect different government organisations by sharing their ideas and thus learning from each other. Governments are advised to openly appreciate citizens' contribution to the innovation process. A side effect of metavoicing is governments being able to get into direct contact with citizens. Previously, government communication has mainly been mediated through mass communication, which could lead to misunderstandings and misinterpretations (Fisher Liu and Horsley 2007). Using social media, governments can directly react to any information published about them. Governments can benefit from association by attracting further 'followers' for their social media site and by creating new associations between governments and other actors. Furthermore, governments can explicitly get into contact with groups that are supposed to hold a critical view of government activities and try to integrate them into the innovation design phase. Persistence is also useful for governments in terms of learning about communication behaviour in social media by analysing the conversation streams and citizens' reactions.

We expect our research to make a significant contribution to theory, by matching capabilities organisations need to possess for successful service innovations with affordances provided by different social media technologies. Generally, based on the combination of two theoretical foundations dynamic capability theory and affordances theory - the developed framework can be classified as universally valid and hence, can be utilised in different scenarios and settings. More specifically, we defined several social media affordances for engaging with customers respectively citizens aiming at the development of service innovations. These affordances can be successfully utilised to support the capabilities of signalling, conceptualisation, configuration, and learning. For the support of coproducing and orchestration as well as scaling and stretching none of the identified affordances could be leveraged reasonably. From a practical perspective, organisations and in particular governments can use the presented framework to design their social media strategy and to identify potential improvements. With respect to each capability they can compare their actual social media activities to potential application possibilities afforded by social media. As organisations are forced to constantly react to technological evolutions, we present a structured approach to develop a social media strategy for organisations.

This research is subject to two main limitations that will be part of future research. First of all, we tested our framework in the context of government, which is defined as non-profit organisation. Although it 
worked quite well, generalisability is not given yet. Therefore, we need to apply the presented framework to further domains, each considering specific requirements. Second, as this research is only conceptually we need to test it within real settings. With respect to these limitations, future research will concentrate on qualitative and quantitative analyses, evaluating whether the framework is applicable in each domain and thereby universally valid. Furthermore, differences and best practices between public and private sector strategies regarding the encouragement of capabilities for open innovation strategies need to be identified.

\section{REFERENCES}

Barnett, A. 2013. "The Battle for Taksim Square and the Gezi Park Commune," Retrieved 1 August, 2013, from http://www.opendemocracy.net/anthony-barnett/battle-for-taksim-square-and-gezipark-commune.

Bekkers, V., Van Duivenboden, H., and Thaens, M. 2006. "Public innovation and information and communication technology: relevant background and concepts," in Information and Communication Technology and Public Innovation, V. Bekkers, H. van Duivenboden, and M. Thaens (eds.), Amsterdam, Netherlands: IOS Press, pp. 3-21.

Bollen, J., Pepe, A., and Mao, H. 2011. "Modeling public mood and emotion: Twitter sentiment and socio-economic phenomena," Proceedings of the Fifth ICWSM11.

Bolton, R. N., Parasuraman, A., Hoefnagel, A., Migchels, N., Kabadayi, S., Gruber, T., Komarova, Y., and Solnet, D. 2013. "Understanding Generation Y and their use of social media: a review and research agenda," Journal of Service Management (24:3), pp. 245-267.

Boyd, D. M., and Ellison, N. B. 2007. "Social Network Sites: Definition, History, and Scholarship," Journal of Computer-Mediated Communication (13:1), pp. 210-230.

Bélanger, F., and Carter, L. 2008. "Trust and risk in e-government adoption," The Journal of Strategic Information Systems (17:2), pp. 165-176.

Chaston, I. 2012. "Open innovation and public administration: transformational typologies and business model impacts," International Journal of Public Administration (35:4), pp. 248-258.

Chun, S. A., and Warner, J. 2010. "Finding information in an era of abundance: Towards a collaborative tagging environment in government," Information Polity (15), pp. 89-103.

Collis, D. J. 1994. "Research Note: How Valuable are Organizational Capabilities?," Strategic Management Journal (15:1), pp. 143-152.

Edwards, A. 2006. "Empowering Communities for Environmental Decision-Making: Innovative Partnerships in Cleveland (USA)," in Information and Communication Technology and Public Innovation: Assessing the ICT-Driven Modernization of Public Administration, V. Bekkers, H. van Duivenboden, and M. Thaens (eds.), Amsterdam, Netherlands: IOS Press, pp. 175-191.

Feller, J., Finnegan, P., and Nilsson, O. 2010. "Open innovation and public administration: transformational typologies and business model impacts," European Journal of Information Systems (20:3), pp. 358-374.

Fisher Liu, B., and Horsley, J. S. 2007. "The Government Communication Decision Wheel : Toward a Public Relations Model for the Public Sector," Journal of Public Relations Research (19:4), pp. 377-393.

GoPetition. 2013. "How to Create a Petition," Retrieved 1 August, 2013, from https://www.facebook.com/notes/gopetition/how-to-create-a-petition/122104031162717.

Gregurec, I., Vranesevic, T., and Dobrinic, D. 2011. "The Importance of Database Marketing in Social Network Marketing," International Journal of Management Cases (13:4), pp. 165-172. 
Helfat, C. E., and Peteraf, M. A. 2003. "The Dynamic Resource-Based View: Capability Lifecycles," Strategic Management Journal (24:10), pp. 997-1010.

Den Hertog, P., Van Der Aa, W., and De Jong, M. W. 2010. "Capabilities for Managing Service Innovation: Towards a Conceptual Framework," Journal of Service Management (21:4), pp. 490-514.

Hofmann, S., Räckers, M., Beverungen, D., and Becker, J. 2013. "Old Blunders in New Media? How Local Governments Communicate with Citizens in Online Social Networks," in Proceedings of the 46th Hawaii International Conference on Systems Sciences, pp. 1-10.

Johnson, S. P., Menor, L. J., Roth, A. V., and Chase, R. B. 2000. “A Critical Evaluation of the New Service Development Process: Integrating Service Innovation and Service Design," in New Service Development - Creating Memorable Experiences, J. A. Fitzsimmons and M. J. Fitzsimmons (eds.), Thousand Oaks, CA: Sage Publications, pp. 1-32.

Jong, J. P. J. De, and Vermeulen, P. a. M. 2003. "Organizing successful new service development: a literature review," Management Decision (41:9), pp. 844-858.

Kaplan, A. M., and Haenlein, M. 2010. "Users of the World, Unite! The Challenges and Opportunities of Social Media.," Business Horizons (53:1), pp. 59-68.

Kinder, T. 2010. "E-Government Service Innovation in the Scottish Criminal Justice Information System," Financial Accountability \& Management (26:1), pp. 21-41.

Koldzin, D. 2011. "Government Instruments to Support Open Innovation-Experiences from EU Countries,” ACTA TECHNICA CORVINIENSIS - Bulletin of Engineering (4), pp. 35-39.

Kotler, P. 1988. Marketing Management: Analysis, Planning, Implementing and Control, (6th ed.) Englewood Cliffs, NJ: Prentice Hall.

Lee, G., and Kwak, Y. H. 2012. "An Open Government Maturity Model for social media-based public engagement," Government Information Quarterly (29:4), pp. 492-503.

Lee, S. M., Hwang, T., and Choi, D. 2012. "Open innovation in the public sector of leading countries," Management Decision (50:1), pp. 147-162.

Leonardi, P. M. 2011. "When Flexible Routines Meet Flexible Technologies: Affordance, Constraint, and the Imbrication of Human and Material Agencies," MIS Quarterly (35:1), pp. 147-167.

Majchrzak, A., Faraj, S., Kane, G. C., and Azad, B. 2013. "The Contradictory Influence of Social Media Affordances on Online Communal Knowledge Sharing," Journal of Computer-Mediated Communication (19:1), pp. 38-55.

Martin, B. 2003. "Knowledge Management and Local Government: Some Emerging Trends," Asia Pacific Management Review (8:1), pp. 43-58.

Menor, L. J., and Roth, A. 2007. "New Service Development Competence in Retail Banking: Construct Development and Measurement Validation," Journal of Operations Management (25:4), pp. 825-846.

Menor, L. J., Tatikonda, M. V., and Sampson, S. E. 2002. "New Service Development: Areas for Exploitation and Exploration," Journal of Operations Management (20:2), pp. 135-157.

Mergel, I. 2011. "Crowdsorced Ideas Make Participating in Government Cool Again," PA Times, pp. 4-7.

Obama, B. 2008. "Transparency and Open Government. Memorandum for the Heads of Executive Departments and Agencies".

Plattfaut, R., Beverungen, D., Hofmann, S., and Räckers, M. 2013. "Unravelling (E-)Government Channel Selection: A Quantitative Analysis of Individual Customer Preferences in Germany 
and Australia," in Proceedings of the 46th Annual Hawaii International Conference on System Sciences, January 7-10, p. 9.

Rishika, R., Kumar, A., Janakiraman, R., and Bezawanda, R. 2013. “The Effect of Customers' Social Media Participation on Customer Visit Frequency and Profitability: An Empirical Investigation," Information Systems (7047), pp. 1-20.

Schumpeter, J. A. 1934. The Theory of Economic Development, Cambridge, MA: Harvard University Press.

Spohrer, J. C., and Maglio, P. P. 2008. "The Emergence of Service Science: Toward Systematic Service Innovations to Accelerate Co-Creation of Value," Production and Operations Management (17:3), 238-246.

Statista. 2012. "Social networking: U.S. users by age group in 2012," Retrieved 1 August, 2013, from http://www.statista.com/statistics/221674/share-of-us-social-network-users-by-age-group/.

Teece, D. J., Pisano, G., and Shuen, A. 1997. "Dynamic Capabilities and Strategic Management," Strategic Management Journal (18:7), pp. 509-533.

Thaa, W. 2013. “'Stuttgart 21' - Crisis or Repoliticization of Representative Democracy?," Politische Vierteljahresschrift (54:1), pp. 1-20.

Thoreson, K., and Miller, T. 2013. "Tapping Technology to Connect With the Public".

Treem, J., and Leonardi, P. 2012. "Social media use in organizations: Exploring the affordances of visibility, editability, persistence, and association," Communication yearbook (36).

\section{ACKNOWLEDGEMENTS}

This paper was written in the context of the research project Networked Service Society (promotional reference APR 10/805) funded by the German Federal Ministry of Education and Research (BMBF).

An earlier version of this paper was presented at the Australasian Conference on Information Systems (ACIS) 2013 in Melbourne, Australia. 